\title{
Artículo especial: Hacia los derechos de los pacientes
}

\author{
Towards patient's rights
}

Ricardo Teodoro Ricci*

"...cada uno de nosotros es culpable ante todos, por todos y por todo..."

F. Dostoievsk ${ }^{1}$

Ricardo Teodoro Ricci Hacia los derechos de los pacientes. Evid Actual Pract Ambul. 2015;18(3):91-93.Jul-Sep.

En general, cuando nos enfrentamos con el desafío de tratar los derechos de los pacientes lo hacemos desde nuestra condición de médicos prácticos, es decir, desde la experiencia de haber estado en contacto con personas que han recurrido a nosotros en situación de enfermedad. Naturalmente, es nuestra primera posibilidad de incursionar en el tema, ya que al no ser especialistas en derechos, acudimos a la cotidianeidad de nuestra experiencia.

Otra forma de abordarlo, sería recurrir a la historia de la instauración sociopolítica de los derechos humanos, remontándonos a los orígenes históricos de su reconocimiento y a su puesta en vigencia por medio de declaraciones de consentimiento y difusión universal. Hay otros modos más de incursionar en el tema, algunos quizás más acertados que otros, por ejemplo, más legalistas o más personalistas, más ligadas al derecho natural o más ligadas al derecho positivo, etc.

En nuestro caso sin embargo, al aceptar la propuesta de desarrollar el tema, hemos decidido plantearlo desde su mismísima génesis. Nos pareció original soslayar las declaraciones y apuntar a una mayor profundidad: a aquel lugar, si acaso lo hay, de donde proviene la idea misma de los derechos del hombre.

En este contexto nos vino a la memoria la pregunta filosófica por excelencia: “¿Por qué el ser y no más bien la nada?” La reflexión acerca de por qué las cosas son, cuando podrían no ser. Pregunta de una vigencia y una agudeza sin par. Si acaso esta pregunta, que acompaña a la humanidad occidental desde el siglo V antes de Cristo, fuera contestada, la respuesta a la misma serviría como fundamentación ontológica a todas aquellas cuestiones acerca del ser que se nos ocurriera plantear. Veinticinco siglos después, la pregunta sigue resonando en las mentes de los filósofos, y en los momentos en los que el hombre común se cuestiona acerca de su existencia. Si bien no conocemos una respuesta conclusiva, consideramos que no es prudente desechar ninguno de los innumerables intentos por responderla, ya que no conviene echar por la borda nada del trabajo reflexivo que los seres humanos han efectuado durante tanto tiempo.

A la luz de ese planteamiento, y en un intento de reflexionar en forma profunda, se nos ocurrió -seguramente sin demasiada originalidad-, hacer un cuestionamiento similar: ¿Por qué algo o alguien debería ser poseedor de derechos, cuando podría no serlo? Concretamente, ¿qué es lo que justifica que el ser humano sea pasible de derechos de algún tipo, cuando podría ocurrir que no poseyera derecho alguno?

Esta pregunta, que en un contexto médico suena excesivamente rebuscada y carente de inmediata aplicabilidad, podría guiarnos hacia una respuesta, acaso provisoria, que ayude a iluminar los cimientos de todo derecho: aquellos del paciente y también del médico, los de la comunidad y también los del sistema de salud. Nos ayudaría a definir cuál es el fundamento por el cual alguien puede reclamar genuinamente algo para sí, o bien por qué estaría un profesional obligado a satisfacer la necesidad de alguien, o al menos no avasallar la dignidad de la persona que recurre a él en busca de cuidado.

Parecen preguntas vacías y antojadizas, sin embargo conviene recordar que pensadores de la talla de Maclntyre, al no reconocer principios metafísicos que los justifiquen, dijo de los derechos humanos: "...no existen tales derechos, su creencia es como creer en brujas y unicornios...."; sin olvidar a Alexy, que sostuvo que "...puesto que la existencia de los derechos humanos depende en definitiva de su fundamentación, sólo esa fundamentación determina si los mismos algo son más que una ilusión. El problema de la fundamentación puede sintetizarse en la cuestión de si, y cómo, pueden ser justificadas las normas o reglas morales que con pretensión de prioridad garantizan los derechos universales, fundamentales y abstractos. Esto demuestra que el problema de la justificación de los derechos humanos no es otra cosa que un caso especial del problema general de la fundamentación de las normas morales..."”.

No estamos en condiciones de responder a cuestiones metafísicas elevadas y tampoco nos cabe incurrir en fundamentaciones jurídicas acabadas. Lo que sí creo que puede correspondernos, es hacer un intento de justificación desde nuestro marco teórico y nuestra propia experiencia, o bien desde la osadía genuinamente humana de intentar dar una respuesta a interrogantes que nos inquietan.

\section{Intentos de justificación}

Muchos y diversos caminos han sido recorridos para intentar dar una respuesta a esta cuestión de la fundamentación de los derechos de los hombres. La clasificación más básica es aquella que distingue entre la inexistencia de la posibilidad de una justificación, y la de los que afirman que es viable intentar hacer alguna.

El escepticismo radical, definido a través de la negación básica de la fundamentación de las normas morales puede tener sus raíces en las formas del emotivismo, el decisionismo, el subjetivismo, el relativismo, el naturalismo, o el descontructivismo. El no-escepticismo, sostiene por el contrario, que es posible aducir fundamentos para los derechos humanos, y que se puede formular una pretensión de objetividad, de corrección o de verdad $^{2}$

Convencidos de que desde nuestro lugar de profesionales de la salud sólo nos cabe optar por la segunda de las posiciones, (el no-escepticismo), es menester decir que este campo está muy lejos de resultar homogéneo. En él se dan cita distintos cuerpos de fundamentación entre los que podemos distinguir los siguientes: religioso, biológico, intuitivo, consensual, instrumental, cultural, explicativo y existencial. Todos ellos tienen sus exponentes y su estructura racional complejamente construida. Todos ellos tienen sus fortalezas y sus debilidades, algunos con mayor capacidad inclusiva que otros. A los efectos del presente trabajo no haremos una valoración detallada de cada uno de estos intentos, por el contrario es nuestro propósito plantear un camino que, con todas las debilidades de la opinión emitida por un no experto, pueda apuntar a dar una justificación de los derechos del paciente.

Como dijimos al principio, este intento ha de ser hecho desde distintas vertientes teóricas buscando una integración que satisfaga la práctica. Esta opción por el camino a recorrer, condensará su extrema debilidad y su genuina autenticidad. 


\section{Una propuesta}

Partiremos de la realidad de que el hombre es un ser social, es decir que sólo alcanza grados diferenciales de humanidad en el encuentro con el otro. Pensar al hombre como un ser solitario, ensimismado en la reflexión de sí mismo, nos conduce a un camino de intransitable esterilidad, cuando no de patente irrealidad. La presencia del otro y de su rostro -como diría Levinas ${ }^{4}$ - inaugura el espacio en el que el sí mismo alcanza una identidad inaugural y con el tiempo, una solidez vincular.

Sólo en ese espacio de interacción yo-tú, se reconoce la humanidad del hombre. Dicho en palabras del biólogo chileno Humberto Maturana: “...la emoción que constituye la coexistencia social es el amor, esto es, el dominio de aquellas acciones que constituyen al otro como un legítimo otro en coexistencia con uno, y nosotros, los seres humanos, nos hacemos sociales desde nuestra infancia temprana en la intimidad de la coexistencia social con nuestras madres..." Aquello que Maturana denomina con toda propiedad "amor", en el contexto de publicaciones más académicas, se puede traducir con menos precisión como coexistencia pacífica, cooperación, individuación en entornos sociales, etc. Es de destacar que "amor", significa ni más ni menos que el fundamento de lo social: reconocer al otro como un auténtico otro en que reconocemos semejanzas, y del cual nos distinguimos por nuestras diferencias. Es en el marco de dicho "reconocimiento", que resulta indispensable destacar, ese espacio en el que se descubre que la presencia del otro es sustantiva e imprescindible para el florecimiento de las personas de ambos. Para decirlo con todas las letras: no hay ser humano por fuera de la interacción, por fuera de la relación.

El filósofo Martin Buber ${ }^{6}$ nos dice que hay solo dos palabras primordiales, dos fundamentos desde los cuales podemos entender nuestra presencia en el mundo y entre los hombres. La primera de ellas es el par "yo-eso". Cuando estamos ante una instancia de conocimiento en la que predomina una actitud descriptiva y cuantificadora (largo/corto, alto/bajo, blanco/negro, me gusta/no me gusta) estamos en una relación "yo-eso" en la que predomina la objetivación de lo conocido desde un sujeto cognoscente. Por otro lado, cuando estamos en una relación "yo-tú", las categorías de lo objetivo y lo subjetivo tienden a fundirse promoviendo un intercambio cualitativo que impacta significativamente en los componentes de esa provisoriamente inseparable díada.

Una cosa es ver las estadísticas de la pobreza en la Argentina, su relación con la distribución de los bienes y constatar la profunda inequidad social, y otra es enfrentar el rostro del que acude a nosotros en extrema necesidad y nos interpela desde su desvalimiento. Lo primero es un conocimiento objetivo, lo segundo nos cuestiona personalmente, nos aprieta las tripas, nos conmina a dar una respuesta, nos llama a asumir mi responsabilidad ante ese individuo que tenemos ante nosotros. Para Buber, "...la ética no comienza en el otro, sino en la relación recíproca entre el yo y el tú. Uno comienza por uno mismo pero no aspira a sí, ni se preocupa por sí mismo, más bien se dirige hacia el otro esperando el misterio del otro, a la espera de su gracia..."

Para Emmanuel Levinas ${ }^{4}$ el rostro del otro es aún más fuerte y determinante; y su presencia inaugura un espacio de responsabilidad. Exige de nosotros una respuesta concreta y comprometida, su demanda merecida se potencia a la condición de lo imperativo en la que los derechos del otro están por encima de los nuestros. El rostro del otro se nos aparece en forma de desvalimiento, de privación y de necesidad. Lo dice de diferentes modos, y en uno de ellos asevera que no nos damos cuenta de lo ricos que somos hasta que nos enfrentamos con el otro. En el encuentro advertimos que no somos ricos porque tenemos más de lo que necesitamos, sino porque el otro tiene menos de lo que él necesita. Escribe: “...esta mirada que suplica y demanda, que puede suplicar en tanto que demanda, privada de todo porque tiene derecho a todo, esta mirada precisamente es la epifanía del cara a cara. La desnudez del rostro es indigencia. Reconocer al Otro es reconocer el hambre. Reconocer al otro es dar. Pero es darle al maestro, al señor, a aquel a quien nos acercamos en una dimensión de altura..."

Como podemos apreciar en estos autores, la presencia del otro, así como el encuentro con él son determinantes para detonar el espacio de los derechos, de las libertades y de las responsabilidades. Ambos fortalecen y profundizan la significación del encuentro entre los hombres. Si se hace un recorrido por las experiencias de vida de cada uno de nosotros, seguramente se destacarán innumerables momentos que pueden ser vistos desde esta perspectiva. Encuentros en los que nos vimos restringidos por unos otros avasallantes y autoritarios, encuentros en los que percibimos cierta simetría, o bien encuentros en los que nuestra superioridad alcanzaba el grado de evidencia; pueden ser, todos ellos, vistos desde la fértil mirada de los autores citados. En todos los casos, el evento del encuentro con cualquier otro, abre necesariamente un espacio de reconocimiento de diferencias, de desafíos de identidad, y de incuestionable surgimiento de la responsabilidad.

Además, si recordamos la premisa kantiana de que ningún hombre debe ser tomado como un medio, sino como un fin en sí mismo, y que lo que reclamamos para nosotros sólo alcanza valor ético si puede ser aplicado con amplitud de universalidad, el camino para la fundamentación de los derechos de los hombres adquiere evidencia de racional consolidación.

Todo derecho humano se fundamenta en un imperativo ético. Las declaraciones, las leyes y los códigos se encuentran en la delicada tarea de asumirlos, reconocerlos y establecerlos normativamente. Como sostiene Bulygin , "...de aquí parece inferirse que cuando un orden jurídico positivo otorga derechos humanos, en realidad no hace otra cosa que reconocer derechos ya preexistentes e independientes de lo que establece el orden jurídico en cuestión...”. Este último autor sostiene que los derechos humanos se tratan de reglas o principios de un sistema moral, por lo tanto son, en un sentido originario, derechos morales cuya existencia es independiente del reconocimiento que de ellos haga el sistema jurídico: "...la fundamentación de los derechos del ser humano descansa, pues, en la hipótesis de un sistema moral objetivamente válido, accesible al conocimiento humano..."?.

Desde la perspectiva clásica en medicina, Pace y col. ${ }^{8}$ sostienen que "...los derechos humanos son una serie de exigencias y pretensiones ético-jurídicas y políticas que, en virtud de la dignidad de la persona humana, se postulan frente a aquellas formas de poder social que la niegan o la ponen en peligro. Expresan valores como la libertad, la igualdad y la solidaridad, y tienden a ser reconocidos en legislaciones nacionales e internacionales..." Coincidimos con estas autoras, e intentamos por nuestra parte, consolidar la convicción de que los derechos de los hombres representan cuestiones más básicas y fundamentales: son seres vivos provistos de autoconciencia, libertad y voluntad que, ante la ineludible realidad y necesidad de tener que desarrollarse en medio de semejantes que a la vez los limitan y los potencian, generan modos de resguardar la convivencia, salvaguardando a la vez la expresión plena de sus facultades y potencialidades. Los derechos de nuestros pacientes 
Una vez que hemos esbozado las bases y fundamentos de todo derecho de las personas, la mera enunciación y justificación de los derechos particulares y específicos tiene sabor a redundancia y obviedad. Permítasenos insistir que una vez que se han dado pasos sólidos en la fundamentación de los derechos y de haber consolidado los cimientos que los sustentan, alcanzamos la convicción de que todo derecho positivo (enunciado en constituciones, leyes o reglamentaciones de todo tipo) se trata de un intento de hacer visible y evidente lo medular e incuestionable. Dados los antecedentes de avasallamiento y menosprecio de esos derechos por parte de los mismos seres humanos, se ha hecho imprescindible su enumeración y reglamentación. Aun así, es preciso reconocer que debajo de cada precisión, resuena el fundamento de un yo que se encuentra con un tú que le reclama: -No me mates, soy imprescindible para ti, me debes la existencia como persona.

Clásicamente los derechos humanos se dividen en:

1) de primera generación, los que hacen referencia a lo civil y lo político,

2) de segunda generación, los derechos económicos, sociales y culturales,

3) de tercera generación, los derechos de los pueblos y las minorías.

Mucho ha tenido que transitar la humanidad para reconocer y consensuar algo que se halla intrínseco en su naturaleza. Ese recorrido, a la vez que destaca los logros conseguidos, nos habla de la estrechez de mirada, del egocentrismo insano y de la miseria de los hombres.

En 1973, la Asociación Norteamericana de Hospitales aprobó la Carta de Derechos del Paciente y el Departamento Federal de Salud sugirió su implementación en los hospitales y demás centros de salud, y su divulgación entre los pacientes que asistían a ellos. Posteriormente y en distintas oportunidades, otras organizaciones nacionales e internacionales se hicieron eco de esta problemática, y emitieron largas listas enumerando los derechos de los pacientes. Es menester reconocer que, en el contexto de una práctica médica despersonalizada y deshumanizada, esas listas son tan indispensables como soslayables. Consideramos que cuanto más se deben mencionar casos y situaciones es porque más y más se olvida la esencia. Cuanto más se deben enunciar derechos que ya se encuentran implícitos en pronunciaciones más generales, más se pone en evidencia la estrechez de miras, la insensibilidad y el suicida desprecio por el otro.

Teniendo en cuenta que todo derecho humano se fundamenta en un imperativo ético, ¿es necesario que se nos diga que el paciente tiene derecho a una atención considerada y respetuosa? ¿es necesario que se nos recuerde que el paciente tiene derecho a morir con dignidad?

Habiendo hecho referencia a la relación primordial yo-tú, ¿es necesario insistir en que el paciente tiene derecho a la confidencialidad de su información y asistencia?

Habiendo insistido en el rostro del otro que acontece ante nosotros con un pedido de auxilio esencial, de supervivencia, ¿es imprescindible incluir en una lista que la persona debe ser respetada en su dignidad e identidad individual y cultural, y no ser discriminada por cualquier razón o motivo?

Sí, parece que es necesario que una lista de cotejo en la que debemos tildar los diferentes ítems, nos lo recuerde permanentemente. Algo nos pasa a los hombres y a los profesionales de la salud en particular, que necesitamos ese tipo de recordatorio. Algo se interpone entre nosotros como para que necesitemos de una ayuda memoria en frente de otro ser humano.

\section{A modo de conclusión}

Ante el estrepitoso fracaso del iluminismo y del imperio de la razón de mediados del siglo $\mathrm{XX}$, se impone vislumbrar una ética enriquecida en sus fundamentos, una ética en la que la razón forme parte de la valoración del bien, pero en la que también tengan un lugar de privilegio la intuición y la emoción.

Parece adecuado que se deje de considerar al hombre como una razón encarnada para dejar un espacio jerarquizado al "siento, luego soy". Como sostiene Tealdi ${ }^{9}$ " "...es por eso que no podemos encontrar lo particular en lo general, sino que en modo inverso descubrimos lo general en lo particular de cada vivencia. Es en el cuerpo de cada paciente donde tenemos experiencia del valor de la vida, de la dignidad y de la liber$\operatorname{tad} . . . "$.

Puede ocurrir que, en pos de cumplir con la lista de derechos enunciada, con los principios invocados y con las declaraciones reglamentadas, nos olvidemos de nuestra sensibilidad y del otro presente. Frente al paciente en el consultorio, o bien al lado de su cama en el hospital, es preferible hacer contacto con la sensibilidad de nuestras intuiciones para hacerlas inteligibles. De allí que los derechos humanos, y con ellos los del paciente, no se basen tanto en reglas, sino en imperativos de la conciencia que surgen en instancias de encuentro con el otro que nos interpela. Es cierto, una vez logrados los cimientos, y sólo si son logrados, es conveniente que los derechos sean reglamentados y expresados positivamente con el objetivo de conformar un cuerpo normativo sintético de fácil accesibilidad.

Quede la pregunta: junto con la evolución civilizatoria, ¿habrá acaso una evolución de sistemas morales? ¿puede esperarse algo así?"10

A ambas preguntas, la tortuosa historia del hombre responde: Sí

Recibido el 03/11/15 y aceptado el 11/11/15

\section{Referencias}

1. Citado por: Sábato E. La resistencia, Editorial Planeta / Seix Barral, Buenos Aires, Argentina, 2000.

2. Mac Intyre A. After Virtue A Study in Moral Theory 2007 University of Notre Dame Press.

3. Alexy R. ¿Derechos humanos sin metafísica? Edición digital a partir de Doxa : Cuadernos de Filosofía del Derecho, núm. 30 (2007), pp. 237-248.

4. Levinas, E. Totalidad e infinito. Ensayos sobre la exterioridad. Sígueme, Salamanca, 1999.

5. Maturana $\mathrm{H}$ y col. Amor y juego: Fundamentos olvidados de lo humano. Colección Experiencia Humana. Ed. Instituto de Terapia Cognitiva; 1993.

6. Atterton P y col. Levinas y Buber. Diálogos y diferencias. Limod, Buenos Aires. 2006.

7. Bulygin E. Sobre el estatus ontológico de los derechos humanos. Doxa, Cuadernos de Filosofía del Derecho, 4, 1987

8. Pace R y col. Iniciación a la bioética. Ediciones del Hospital Italiano de Buenos Aires, Argentina, 2008.

9. Tealdi J. Los derechos de los pacientes desde una bioética de los derechos humanos. (Prefacio), en Oscar Garay, Derechos fundamentales de los pacientes, Bs. As., Editorial Ad Hoc, 2003, págs. 35-55.

10. Lola Stepkes F. Nuevas cavilaciones de Andrenio. Ril editores. Santiago de Chile, 2015. 